\title{
Multiple Antenna-Aided Spectrum Sensing Using Energy Detectors for Cognitive Radio
}

\author{
Seung-Hoon Hwang and Jun-Ho Baek \\ Dongguk University-Seoul, \\ Korea
}

\section{Introduction}

Recently a spectral scarcity has arisen as a serious problem, because current static frequency allocation schemes cannot further accommodate an increasing number of devices requesting higher data rate. Therefore, CR (cognitive radio) technique has been considered as a potential solution to improve spectrum utilization by sharing the spectrum. In this chapter, the main concept of CR was introduced.

\subsection{Motivation}

The demand for higher data rates is increasing as a result of the transition from voice communications to multimedia applications such as video streaming service, photo mail, and DMB (Digital Multimedia Broadcasting: both satellite or terrestrial type employed in Korea). Generally, wide bandwidth is required to achieve high data rate properly. As you know, most of popular radio spectrums are already assigned. Additional spectrum is not enough to be assigned for new application service. The other problem is that spectrum utilization less than $3 \mathrm{GHz}$ concentrates only in several frequency bands, while the majority of frequency bands are inefficiently utilized. According to the FCC's (Federal Communications Commission) report by spectrum policy task force, the usage of allocated spectrum varied around $15 \%$ to $85 \%$ depending on temporal and geographic situations. Therefore, the new paradigm of using spectrum more efficiently has urged to create a new wireless communication technology.

\subsection{Overview of cognitive radio}

IEEE 802.22 based WRAN (wireless regional area network) devices sense TV channels and identifies opportunities for transmission. Figure 1-1 shows example of deployment for IEEE 802.22 WRAN. Recently, IEEE 802.22 standards have included cognitive features for the first time. We may say the trend is targeting at this direction, even though it is difficult to expect a wireless standard which is based on wideband spectrum sensing and opportunistic exploitation of the spectrum.

In CR terminology (I. Mitola, J. \& J. Maguire, 1999), primary or incumbent user can be defined as the users who have higher priority rights on the usage of a specific part of the spectrum. On the other hand, secondary users with lower priority exploit this spectrum in such away that they do not cause interference to primary users and other secondary users. 


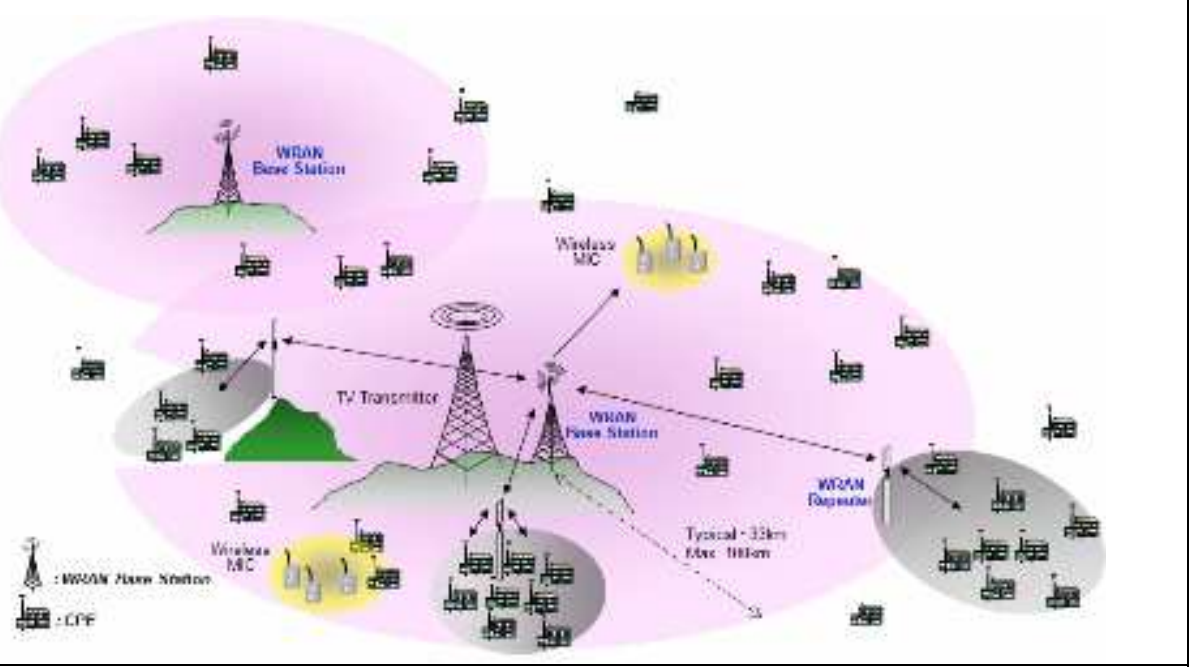

Fig. 1-1. IEEE 802.22 WRAN Deployment Scenario

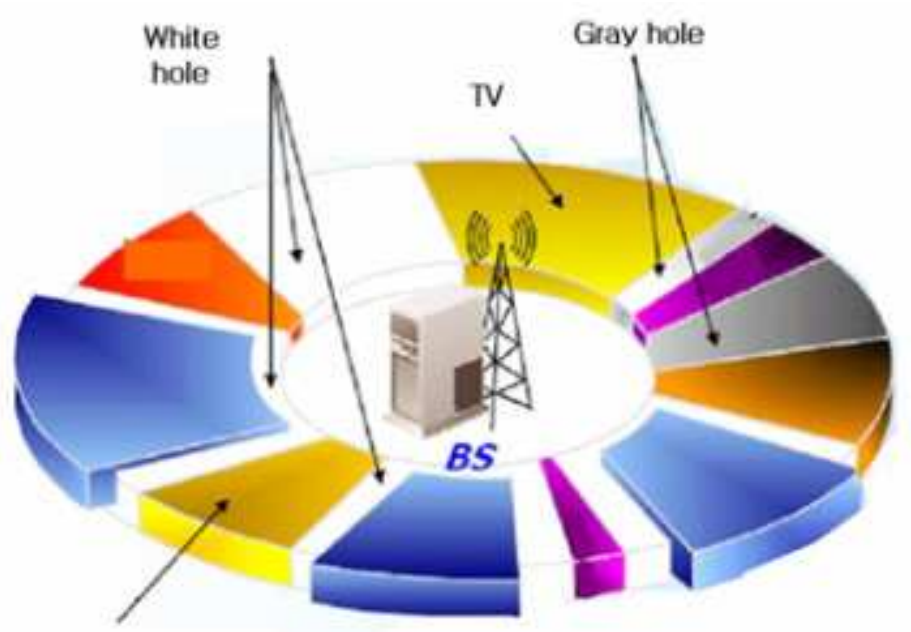

Incumbent user

Fig. 1-2. Spectrum Hole Classification (Ian F Akyildiz et al)

In Figure 1-2, spectrum hole can be classified as a black space, white space and gray space. In the white space, there is no interference except noise for the frequency. The Gray space indicated that this spectrum is partially used under acceptable interference. The black space is occupied by incumbent user. The CR technique is aiming at usage of unoccupied spectrum such as the white space or the gray space by adopting the concept of dynamic and autonomous spectrum management, while ensuring the right of privileged primary users. 
Therefore, the secondary users should monitor licensed bands and transmit their signals opportunistically whenever no primary signal is detected.

Main functionalities of the CR concept are supported by the ability to measure, sense, learn, and be aware of the parameters related to the radio channel characteristics, the availability of spectrum and power, radio' $\mathrm{s}$ operating environment, user requirements and applications, available networks (infrastructures) and nodes, local policies, and the other operating restrictions .

In this chapter, we focus on the spectrum sensing scheme which is the most crucial part to make the CR functionality realized. In Chapter 2, we explain the applicable spectrum sensing methods as well as the cooperative sensing concept. The proposed sensing method was introduced in Chapter 3. Various sensing performances are represented and compared in Chapter 4. Finally, our conclusions were given in Chapter 5.

\section{Various spectrum sensing methods}

In order to protect the primary user from the secondary users, the spectrum sensing is a key function to decide whether frequency band is empty or not. Generally, various methods such as matched filter detection, cyclostationary feature detection and energy detection have been categorized for the spectrum sensing. In this chapter, we will briefly review several spectrum sensing methods and derive analytical performance of energy detector under AWGN channel environment case.

\subsection{Matched filter detection}

Matched-filtering is known as the optimum method for detection of the primary users, when the transmitted signal is known. (J. G. Proakis, 2001) The main advantage of the matched filtering is that it takes short time to achieve the spectrum sensing under a certain value of the probability of false alarm or the probability of misdetection, compared to the other methods (R. Tandra \& A. Sahai, 2005). However, the matched-filtering requires the perfect knowledge of the primary users' signaling features such as bandwidth, operating frequency, modulation type and order, pulse shaping, and frame format. Moreover, the implementation complexity of sensing unit is impracticably large since the CR needs receivers for all signal types (D. Cabric et al., 2004). Another disadvantage of the match filtering is large power consumption, because various receiver algorithms need to be executed for detection.

\subsection{Cyclostationary feature detection}

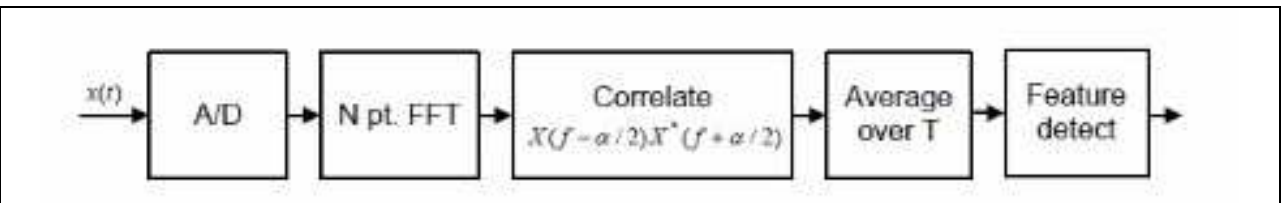

Fig. 2-1. The Structure of Cyclostationary Feature Detector

In the Figure 2-1, cyclostationary features are caused by the periodicity in the signal or its statistics such as mean and autocorrelation or they can be intentionally induced to assist spectrum sensing(O. A. Dobre, et al., 2008), (Mahapatra R \& Krusheel, M, 2008). The 
cyclostationarity-based detection algorithms can differentiate noise from the primary user' signals. This is coming from the fact that the noise is WSS(wide-sense stationary) with no correlation while modulated signals are cyclostationary with spectral correlation due to the redundancy of signal periodicities. Furthermore, the cyclostationarity can be used to distinguish among different types of transmissions. CSD(Cyclic Spectral Density) function of a received signal Eq. (1) can be calculated as follow. (U. Gardner, WA ,1991)

$$
\begin{gathered}
s(f, \alpha)=\sum_{\tau=-\infty}^{\infty} R_{y}^{\alpha}(\tau) e^{-j 2 \pi f \tau} \\
R_{y}^{\alpha}(\tau)=E\left[y(n+\tau) y^{*}(n-\tau) e^{j \pi 2 \alpha n}\right]
\end{gathered}
$$

where $R_{y}^{\alpha}(\tau)$ in Eq. (2) is the $\mathrm{CAF}$ (Cyclic Autocorrelation Function) and is the cyclic frequency. The CSD function outputs peak values when the cyclic frequency is equal to the fundamental frequencies of transmitted signal $x(n)$. The cyclic frequencies can be assumed to be known (M. Ghozzi, et al., 2006).

\subsection{Energy detector}

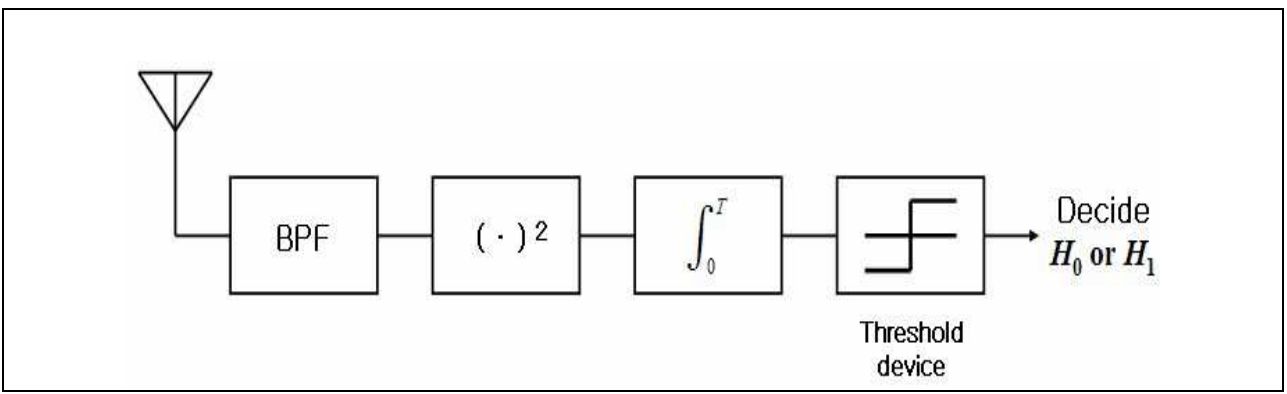

Fig. 2-2. The Structure of Energy Detector

The Figure 2-2 shows the block diagram of a conventional energy detector; the received signal is passed through the BPF(band-pass filter), squared, integrated during the required time, and then compared to a threshold which depends on the noise floor (H. Urkowitz, 1967). In practice, the threshold is chosen to fulfill a certain false alarm rate (D. Cabric et al., 2004). The energy detection method is attractive because it is possible to be applied regardless of the primary signals type and it is quite simple to implement.

Let us assume that the received signal has the following simple form . (H. Urkowitz, 1967)

$$
\left\{\begin{array}{l}
y(t)=n(t), H_{0} \\
y(t)=h(t) * x(t)+n(t), H_{1}
\end{array}\right.
$$

Where $x(t)$ indicates the transmitted signal by the primary user, $n(t)$ denotes the AWGN and $\mathrm{h}(\mathrm{t})$ denotes the amplitude of the channel impulse response. Output $\mathrm{y}(\mathrm{t})$ is the received signal from the secondary user. This is equivalent to distinguishing between the following two hypotheses $\left(\mathrm{H}_{0}\right.$ or $\left.\mathrm{H}_{1}\right)$, its property is known as a central Chi-square distribution and a non-central Chi-square distribution, respectively . (H. Urkowitz, 1967) 


$$
y(t)=\left\{\begin{array}{l}
X_{2 m}^{2}, H_{0} \\
X_{2 m}^{2}(2 \gamma), H_{1}
\end{array}\right.
$$

where, $2 \mathrm{~m}$ is degree of freedom, $\gamma$ is signal-to-noise ratio (SNR), $2 \gamma$ is non-centrality factor, $\mathrm{m}$ is product of time and bandwidth. $X_{2 m}^{2}$ is a Chi-square distribution and $X_{2 m}^{2}(2 \gamma)$ is a noncentral Chi-square distribution its probability of density function known as follow (V. I. Kostylev, 2002).

$$
f_{Y}(y)=\left\{\begin{array}{l}
\frac{1}{2^{m} \Gamma(m)} y^{(m-1)} e^{-\frac{y}{2}}, H_{0} \\
\frac{1}{2}\left(\frac{y}{2 \gamma}\right)^{\frac{(m-1)}{2}} e^{-\frac{2 \gamma+y}{2}} I_{(m-1)}(\sqrt{2 \gamma y}), H_{1}
\end{array}\right.
$$

Commonly, a detector has two types of error events. When channel is really vacant $\left(\mathrm{H}_{0}\right)$, the detector can decide that the channel is occupied. The probability of this undesired event is the probability of a false alarm, denoted as $\mathrm{P}_{\mathrm{FA}}$. When only noise is existing, the $\mathrm{P}_{\mathrm{FA}}$ of energy detector can be calculated exactly, refer to Eq. (6). $\mathrm{P}_{\mathrm{FA}}$ should be kept as small as possible in order to prevent under utilization of transmission opportunities.

$$
\begin{gathered}
P_{F A}=P\left(y>\lambda \mid H_{0}\right) \\
=\int_{\lambda}^{\infty} \frac{1}{2^{m} \Gamma(m)} y^{(m-1)} e^{-\frac{y}{2}} d y \\
=\frac{1}{2^{m} \Gamma(m)} \int_{\lambda}^{\infty} y^{(m-1)} e^{-\frac{y}{2}} d y
\end{gathered}
$$

Making a change of variables $u=\frac{y}{2}$ in Eq.(8)

$$
\begin{gathered}
=\frac{1}{\Gamma(m)} \int_{\lambda}^{\infty} u^{(m-1)} e^{-u} d u \\
=\frac{\Gamma(m, \lambda / 2)}{\Gamma(m)}
\end{gathered}
$$

where, $\Gamma(u)$ gamma function defined in Eq. (11) and (M. Abramowitz and I. Stegun, 1970)

$$
\int_{0}^{\infty} t^{u-1} e^{(-t)} d t
$$

and $\Gamma(\alpha, x)$ is incomplete Gamma function upper bound in Eq. (12)

$$
\int_{x}^{\infty} t^{\alpha-1} e^{(-t)} d t
$$


Meanwhile, the detector may decide that the channel is vacant when channel is actually occupied $\left(\mathrm{H}_{1}\right)$. The probability of this undesired event is referred as the probability of misdetection, denoted as $\mathrm{P}_{\mathrm{MD}}$.

$$
P_{M D}=1-P_{D}
$$

And one minus the probability of misdetection is the probability of detection as $\mathrm{P}_{\mathrm{D}}$. When only noise is existing, the $P_{D}$ of energy detector can be calculated exactly, refer to Eq. (14)

$$
\begin{gathered}
P_{D}=P\left(y>\lambda \mid H_{1}\right) \\
=\int_{\lambda}^{\infty} \frac{1}{2}\left(\frac{y}{2 \gamma}\right)^{\frac{(m-1)}{2}} e^{-\frac{2 \gamma+y}{2}} I_{(m-1)}(\sqrt{2 \gamma y}) d y
\end{gathered}
$$

Change non-centrality parameter corresponds to $u=m \gamma$ in Eq. (15)

$$
=\int_{\lambda}^{\infty} \frac{1}{2}\left(\frac{y}{2 m \gamma}\right)^{\frac{(m-1)}{2}} e^{-\frac{1}{2}(y+2 m \gamma)} I_{(m-1)}(\sqrt{2 m \gamma y}) d y
$$

Change variables $z=\sqrt{y}$ in Eq. (16)

$$
\begin{gathered}
=\frac{1}{(\sqrt{2 m \gamma})^{m-1}} \int_{\sqrt{\lambda}}^{\infty} z^{m} e^{-\frac{1}{2}\left(z^{2}+2 m \gamma\right)} I_{(m-1)}(z \sqrt{2 m \gamma}) d z \\
=Q(\sqrt{2 m \gamma}, \sqrt{\lambda})
\end{gathered}
$$

where, $Q_{m}(a, b)$ is generalized Marcum Q-function, defined as Eq. (19), and modified Bessel function of the first kind of $\mathrm{m}-1$ order is Eq. (20) (21). Refer to (A. H. Nuttall, 1975)

$$
\begin{gathered}
Q_{m}(a, b)=\frac{1}{a^{m-1}} \int_{b}^{\infty} x^{m} e^{\left(-\frac{x^{2}+a^{2}}{2}\right)} I_{m-1}(a x) d x \\
I_{\alpha}(x)=i^{-\alpha} J_{\alpha}(i x) \\
J_{\alpha}(x)=\sum_{m=0}^{\infty} \frac{(-1)^{m}}{m ! \Gamma(m+\alpha)}\left(\frac{x}{2}\right)^{2 m+\alpha}
\end{gathered}
$$

By far, we derived two closed form for probability of detection and misdetection of energy detector under AWGN.

Some of the challenges with energy detector based sensing include selection of the threshold for detecting primary users, inability to differentiate interference from primary users and noise and poor performance under low SNR values. The performance of the energy detection is easily influenced by channel fading, shadowing and interferences (V. I. Kostylev, 2002). As mentioned before, the threshold used in energy detector based sensing algorithms depends on the noise variance. Consequently, a small noise power estimation error causes significant performance loss( A. Sahai et al., 2004). In the following section 2.4, 
we discussed cooperative sensing approach to improve sensing reliability. (Amir Ghasemi \& Elvino S. Sousa, 2005)

\subsection{Cooperative spectrum sensing}

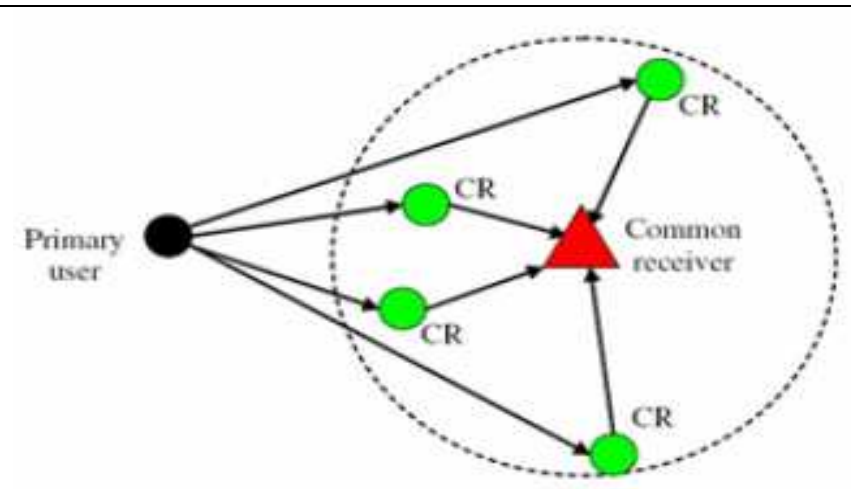

Fig. 2-3. Example of Cooperative Spectrum Sensing (Amir Ghasemi \& Elvino S. Sousa, 2005)

Cooperation is proposed in the literature as a solution to problems that arise in spectrum sensing due to noise uncertainty, fading, and shadowing. (Amir Ghasemi \& Elvino S. Sousa, 2005) The cooperative sensing scheme share sensing information from the independent number of secondary local user. Cooperative sensing decreases the probabilities of misdetection and false alarm considerably. In addition, cooperation can solve hidden primary user problem and it can decrease sensing time. Cooperative spectrum sensing is most effective when local user observe independent fading or shadowing (D. Cabric et al., 2006). The performance degradation due to correlated shadowing is investigated in terms of missing the opportunities. It is found that it is more advantageous to have the same amount of users cooperating over a large area than over a small area . (A. Ghasemi \& E. S. Sousa, 2007)

For example, if we consider the Or-rule as the cooperative decision criterion, where any decision of $\mathrm{H} 1$ from the secondary users decides the channel is occupied. For simplicity, we assume that all $\mathrm{N}$ users experience independent and identically distributed fading with same average SNR. Then the probability of detection, false alarm and misdetection probabilities for cooperative scheme are shown as follows ( P. K. Varshney,1997)

$$
\begin{gathered}
Q_{D}=1-\left(1-P_{D}\right)^{N} \\
Q_{M D}=1-Q_{D} \\
Q_{F A}=1-\left(1-P_{F A}\right)^{N}
\end{gathered}
$$

where $\mathrm{P}_{\mathrm{D}}$ and $\mathrm{P}_{\mathrm{FA}}$ represents the local detection and false alarm probabilities. In (23) and (24), as N gradually increases, $\mathrm{Q}_{\mathrm{MD}}$ and $\mathrm{QFA}$ monotonically decrease.

Challenges of cooperative sensing include developing efficient information sharing algorithms and increased complexity (T. Weiss et al., 2003). In cooperative sensing architectures, the control channel (pilot channel) can be implemented using different 
methodologies. Depending on the system requirements, one of these methods can be selected. Control channel can be used for sharing spectrum sensing results among cognitive users as well as for sharing channel allocation information.

\section{Proposed spectrum sensing method}

For such a cooperative approach, it is prerequisite for the interest user to have several cooperative users who may send information independently. Thus, it is necessary to improve the reliability of the energy detector by a standalone approach. In most of the future mobile and wireless communication systems, spatially-separated multiple antennas are considered at both transmitter as well as receiver (Blostein, S.D \& Leib, H(2003). Out of their advantages, spatial diversity gain is most attractive, which is resulted from the fact that the signals through the multiple antennas go through different paths and thus experience different channel environments.

Therefore, in this chapter, we introduce a novel spectrum sensing structure combining the multiple antennas with the energy detectors for the standalone approach, where a collaborative decision device is employed to improve the sensing reliability.

\subsection{Multiple antenna-aided spectrum sensing method}

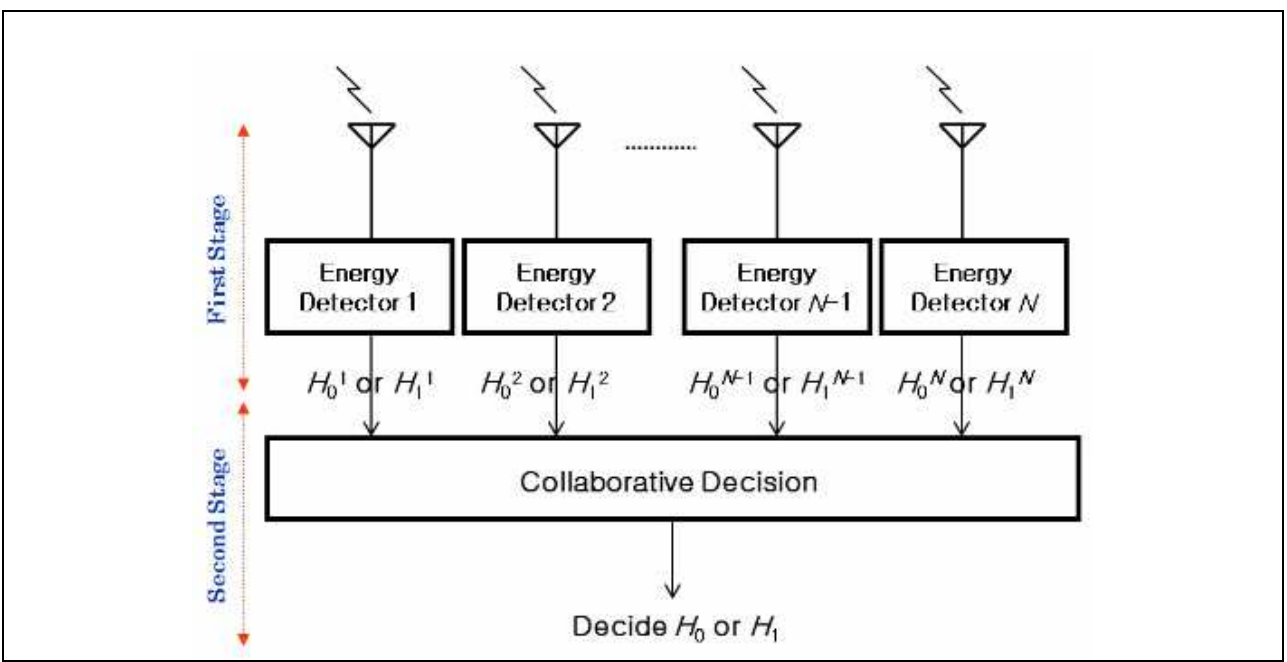

Fig. 3-1. Block Diagram of Multiple Antenna-aided Spectrum Sensing (Jong-Hwan Lee et al. 2008)

We assume that each antenna are separated more than two over wave length of carrier $(2 / \lambda)$. The proposed spectrum sensing scheme is presented in Figure 3-1, and consists of two stages. Tentative decisions are first made by using a conventional energy detector at each antenna. Then, a collaborative decision on whether the band is 'Occupied' (hypothesis $\mathrm{H}_{1}$ ) or 'Vacant' (hypothesis $\mathrm{H}_{0}$ ) is reached by comparing the number of tentative hard decisions with a reference value $K(1 \leq K \leq N)$, with $N$ as the number of antennas. Of course, the output of energy detector can make decision as a soft decision 
instead of hard decision. The results presented in (E. Visotsky et al., 2005) show that soft information-combining outperforms hard information-combining method in terms of the probability of missed opportunity. Intuitively, hard-decisions can understand to perform as good as soft decisions when the number of receiver antenna is high.

Other receiver diversity can attained by combining soft output of each square and integrate operation per diversity node. The Square-Law Combine (SLC), Square-Law Selection (SLS) method is well known micro receiver diversity (Digham, F. F et al., 2007). The SLC method can have slightly better under Rayleigh channel without correlation in the (Digham, F. F et al., 2007).

If one of decision fusion the 'Majority rule' is considered here to make a collaborative decision; in this case, the final decision is dependent on the majority of partial decisions, being defined for a number of antennas exceeding three, $\mathrm{N} \geq 3$.

In the first stage, the energy detector corresponding to the ith antenna, $\mathrm{i}=1, \ldots, \mathrm{N}$, decides on the hypothesis $H_{1}^{(i)}$ or $H_{0}^{(i)}$ by comparing the estimated energy, $y^{(i)}$, with a predefined threshold value, $\lambda$. The two hypotheses are defined as $H_{1}^{(i)}: y^{(i)}(t)=n^{(i)}(t)$, which corresponds to a vacant channel, and , $H_{1}^{(i)_{1}}: y^{(i)}(t)=h(t) * x(t)+n^{(i)}(t)$ which corresponds to an occupied channel. Note that $x(t)$ is the signal transmitted by the primary user, $y^{(i)}(t)$ ,$n^{(i)}(t)$, and $h^{(i)}(t)$ are the signal received by the secondary user, additive white Gaussian noise (AWGN), and channel impulse response corresponding to the ith antenna, respectively, and * represents the convolution operator. Two types of error events can be defined, as mentions before in Chapter 2. Table I describes the example of collaborative decision by Or-Rule criterion.

\begin{tabular}{|c|c|c|c|}
\hline $\begin{array}{c}\text { 1st Energy } \\
\text { Detector }\end{array}$ & 2nd Energy Detector & $\begin{array}{c}\text { 3rdEnergy } \\
\text { Detector }\end{array}$ & $\begin{array}{c}\text { Collaborative final } \\
\text { Decision }\end{array}$ \\
\hline \multirow{4}{*}{$H_{0}$} & \multirow{2}{*}{$H_{0}$} & $H_{0}$ & $H_{0}$ \\
\cline { 2 - 4 } & \multirow{2}{*}{$H_{1}$} & $H_{1}$ & $H_{1}$ \\
\cline { 2 - 4 } & \multirow{2}{*}{$H_{0}$} & $H_{0}$ & $H_{1}$ \\
\cline { 2 - 4 } & $H_{1}^{*}$ & $H_{1}$ & $H_{1}$ \\
\cline { 2 - 4 } & \multirow{2}{*}{$H_{1}$} & $H_{0}$ & $H_{1}$ \\
\cline { 2 - 4 } & & $H_{1}$ & $H_{1}$ \\
\cline { 2 - 4 } & & $H_{0}$ & $H_{1}$ \\
\hline
\end{tabular}

Table 3-1. Example of Or-Rule Criterion for Multiple Antenna-aided Method

\section{Performance analysis and simulation results}

In this Chapter, the average detection probability of Energy detector over three type of channels Rayleigh, shadowing and Suzuki channel are derived. More importantly, performance of our proposed sensing methods also are represented in terms of ROC curve under various environment. Note that average false alarm probability over fading channel is same as AWGN case, since it' s independent of SNR. 


\subsection{Performance analysis of energy detector under fading}

\subsubsection{Rayleigh channel}

The requirement that there be many scatterers present means that Rayleigh fading can be a useful model in heavily built-up city centers where there is no line of sight between the transmitter and receiver and many buildings and other objects attenuate, reflect, refract and diffract the signal.

Let received carrier amplitude is modulated by the fading amplitude $x$, which is random variable with mean square value denote, $\Omega=\overline{x^{2}}$. PDF of fading amplitude $x$ is dependent on the nature of the radio propagation. The instantaneous signal to noise per symbol, $\gamma=x^{2} E_{S} / N_{0}$. Average SNR per symbol represents like, $\bar{\gamma}=\Omega E_{S} / N_{0}$. Therefore there is relation between fading amplitude and SNR .

$$
x=\sqrt{\frac{\gamma}{E_{S} / N_{0}}}=\sqrt{\frac{\Omega \gamma}{\bar{\gamma}}}
$$

Consequently, PDF of $\gamma$ is obtained by changing variable in the expression for the fading PDF $P_{X}(x)$ of $x$.

$$
f_{\gamma}(\gamma)=\frac{f_{X}(x)}{2 \sqrt{\frac{\gamma \bar{\gamma}}{\Omega}}}
$$

If the signal amplitude follows a Rayleigh distribution, then the SNR follows an exponential PDF given by Eq. (27)

$$
f_{X}(x)=\frac{2 x}{\Omega} e^{\left(-\frac{x^{2}}{\Omega}\right)}, x \geq 0
$$

The Rayleigh PDF of $\gamma$ is evaluated by substituting (27) into (26).

$$
\begin{gathered}
f_{\gamma}(\gamma)=\frac{f_{X}\left(\sqrt{\frac{\Omega \gamma}{\bar{\gamma}}}\right)}{2 \sqrt{\frac{\gamma \bar{\gamma}}{\Omega}}} \\
=\frac{\frac{2 \sqrt{\frac{\Omega \gamma}{\bar{\gamma}}}}{\Omega} e\left(-\frac{\sqrt{\frac{\Omega \gamma^{2}}{\bar{\gamma}}}}{\Omega}\right)}{2 \sqrt{\frac{\gamma \bar{\gamma}}{\Omega}}} \\
=\frac{1}{\gamma} e^{\left(-\frac{\gamma}{\gamma}\right)}
\end{gathered}
$$

The average $P_{D}$ in this case, $P_{D}$, Ray, can now be evaluated by averaging Eq.(18) over Eq.(30). refer to (A. H. Nuttall, 1975) 


$$
\begin{aligned}
& \mathrm{P}_{\mathrm{D}^{\prime} \text { Ray }}=\int_{x}^{\infty} Q_{m}(\sqrt{2 m \gamma}, \sqrt{\lambda}) f_{\gamma}(x) d x \\
& \int_{x}^{\infty} Q_{m}(\sqrt{2 m \gamma}, \sqrt{\lambda}) \times \frac{1}{\gamma} e^{\left(-\frac{\gamma}{\gamma}\right)} d \gamma \\
& =e^{-\frac{\lambda}{2}} \sum_{i=0}^{N / 2-2} \frac{\left(-\frac{\lambda}{2}\right)^{i}}{i !}+\left(\frac{2+2 \bar{\gamma}}{2 \bar{\gamma}}\right)^{m-1} \times\left[e^{-\frac{\lambda}{2+2 \bar{\gamma}}}-e^{-\frac{\lambda}{2}}\left\{\sum_{i=0}^{m-2} \frac{\frac{2 \lambda \bar{\gamma}}{2(2+2 \bar{\gamma})}}{i !}\right\}\right] \\
& \approx \frac{\Gamma\left(m-1, \frac{\lambda}{2}\right)}{\Gamma(m-1)}+e^{-\frac{\lambda}{2(1+m \bar{\gamma})}}\left(1+\frac{1}{m_{\bar{\gamma}}}\right)^{m-1} \times\left[1-\frac{\Gamma\left(m-1, \frac{\lambda m \bar{\gamma}}{2(1+m \bar{\gamma})}\right)}{\Gamma(m-1)}\right]
\end{aligned}
$$

\subsubsection{Shadowing channel}

A large obstruction such as a hill or large building obscures the main signal path between the transmitter and the receiver. Normally shadowing is modeled as a log-normal model which is traditionally used to characterize the variation in the local mean power due to shadowing (Kyperountas,. et all, 2007). For shadowing only, $f_{\gamma}(x)$ in equation (35) is lognormal with mean $\mu(\mathrm{dB})$ and a standard deviation $\sigma(\mathrm{dB})$ of $10 \log _{10} \gamma$.

$$
f_{\gamma}(x)=\frac{\xi}{\sqrt{2 \pi} \alpha \gamma} e^{\left(-\frac{\left(10 \log _{10} \bar{\gamma}-\mu\right)^{2}}{2 \alpha^{2}}\right)}
$$

Where, $\xi=10 / \ln 10=4.3429$.

The average $P_{D}$ in this case, $P_{D, L o g}$ can now be evaluated by averaging (18) over (35). Empirical coefficient values for indoor propagation are shown in Table 4-1.

\begin{tabular}{|c|c|c|c|}
\hline Building Type & Frequency of Transmission & $\gamma$ & $\alpha[\mathrm{dB}]$ \\
\hline Vacuum,infinite space & & 2.0 & 0 \\
\hline Retail Store & $914 \mathrm{MHz}$ & 2.2 & 2.18 .7 \\
\hline Grocery Store & $914 \mathrm{MHz}$ & 1.8 & 5.2 \\
\hline Office with hard partition & $1.5 \mathrm{GHz}$ & 3.0 & 7 \\
\hline Office with soft partition & $900 \mathrm{MHz}$ & 2.4 & 9.6 \\
\hline Office with soft partition & $1.9 \mathrm{GHz}$ & 2.6 & 14.1 \\
\hline Textile or chemical & $1.3 \mathrm{GHz}$ & 2.0 & 3.0 \\
\hline Textile or chemical & $4 \mathrm{GHz}$ & 2.1 & $7.0,9.7$ \\
\hline Metalworking & $1.3 \mathrm{GHz}$ & 1.6 & 5.8 \\
\hline Metalworking & $1.3 \mathrm{GHz}$ & 3.3 & 6.8 \\
\hline
\end{tabular}

Table 4-1. Empirical log-normal mean and standard deviation under indoor propagation (T. S. Rappaport, 2002) 


\subsubsection{Suzuki channel}

The combined effect of large scale and small scale fading may be characterized statistically by a Suzuki distribution (M. Patzold et al., 1994). The Suzuki mixture distribution that characterizes the received power can be expressed in terms of signal power, which is obtained by averaging Rayleigh distribution signal power over the conditional density of log-normal mean signal power in Eq. (36).

$$
f_{\gamma}(x)=\int_{0}^{\infty} \frac{1}{\varpi} e^{\left(-\frac{x}{\varpi}\right)} \frac{\xi}{\sqrt{2 \pi} \alpha \varpi} e\left(-\frac{\left(10 \log _{10} \varpi-\mu\right)^{2}}{2 \alpha^{2}}\right) d \varpi
$$

The average $P_{D}$ in this case, $P_{D, \text { suz }}$ can now be evaluated by averaging (18) over (36) refer to (Kyperountas,. et all, 2007).

$$
\begin{gathered}
P_{D, \text { Suz }}=\int_{x}^{\infty} Q_{m}(\sqrt{2 m \gamma}, \sqrt{\lambda}) f_{\gamma}(x) d x \\
=\int_{x}^{\infty} \int_{\varpi}^{\infty} Q_{m}(\sqrt{2 m \gamma}, \sqrt{\lambda}) \frac{1}{\varpi} w^{\left(-\frac{x}{\sigma}\right)} \frac{\xi}{\sqrt{2 \pi} \alpha \varpi} e^{\left(-\frac{\left(10 \log _{10} \pi-\mu\right)^{2}}{2 \alpha^{2}}\right)} d \varpi d x
\end{gathered}
$$

\subsection{Performance analysis of proposed method under fading}

The probability of detection for the proposed sensing method is given by Eq.(39) (41). As you can see this formula is exactly same as cooperative sensing refer to Section 2.4.

$$
P_{D}=\sum_{k=n}^{N}\left(\begin{array}{l}
N \\
k
\end{array}\right) P_{D, i}^{k}\left(1-P_{D, i}\right)^{N-k}
$$

where $P_{D, i}$ is the probability of detection for each output of antennas. The Or-rule fusion can be evaluated by setting $n=1$ in Eq. (39).

$$
P_{D, o r}=1-\left.\left(\begin{array}{l}
N \\
k
\end{array}\right) P_{D, i}^{k}\left(1-P_{D, i}\right)^{N-k}\right|_{k=0}=1-\left(1-P_{D, k}\right)^{N}
$$

The And-rule corresponds to the case n=N, Eq. (39)

$$
P_{D, \text { And }}=\left(P_{D, k}\right)^{N}
$$

Finally, for the case of the majority rule the $n=\lfloor n / 2\rfloor$

$$
P_{D, m a j}=\sum_{k=\lfloor n / 2\rfloor}^{N}\left(\begin{array}{l}
N \\
k
\end{array}\right) P_{D, i}^{k}\left(1-P_{D, i}\right)^{N-k}
$$

\subsection{Simulation environment}

In this paper, the Suzuki channel was considered by calculating MED (Method of Equal Distance). The characteristic of the MED is such that the difference between two adjacent discrete Doppler frequencies is equidistant. (M. Patzold et al. 1996) We assume independent fading and noise on each branch. We consider from two to four antennas at the receive-side 
( $\mathrm{N}$ is $1 \sim 4$ ) and apply the several decision criterion for collaborative decision-making in the second stage of the proposed scheme. The parameters used in simulations are listed in Table 4-2. Note that the $0.33 \mathrm{~ms}$ and $3.3 \mathrm{~ms}$ sampling durations are chosen according to the IEEE 802.22 draft. The primary user is assumed to transmit a BPSK modulated signal. We will select the threshold so as to get $10 \%$ of $\mathrm{P}_{\mathrm{FA}}$ and then calculate the $\mathrm{P}_{\mathrm{MD}}$.

\begin{tabular}{|c|c|}
\hline Parameter & Value \\
\hline Carrier Frequency & $900 \mathrm{MHz}$ \\
\hline Mobile Speed of Secondary User & $30 \sim 110 \mathrm{~km} / \mathrm{h}$ \\
\hline SNR & $3 \mathrm{~dB}$ or $6 \mathrm{~dB}$ \\
\hline Standard Deviation of shadowing & $10 \mathrm{~dB}$ \\
\hline Collaborative Decision Criterion & Or-rule, And-rule, Majority-rule \\
\hline N(number of Receiver Antenna) & $1 \sim 4$ \\
\hline Number of Samples & 105 \\
\hline Sample Period & $0.33 \mathrm{~ms}$ \\
\hline Sensing Duration & $3.3 \sim 13.2 \mathrm{~ms}$ \\
\hline
\end{tabular}

Table 4-2. The Simulation Parameters

\subsection{Performance comparison}

We demonstrate simulation results in terms of complementary ROC curve (plot $\mathrm{P}_{\mathrm{MD}} \mathrm{vs}$. $\left.\mathrm{P}_{\mathrm{FA}}\right)$. The ROC (Receiver Operating Characteristics) curve is known to be a suitable tool for visualizing detector performance.

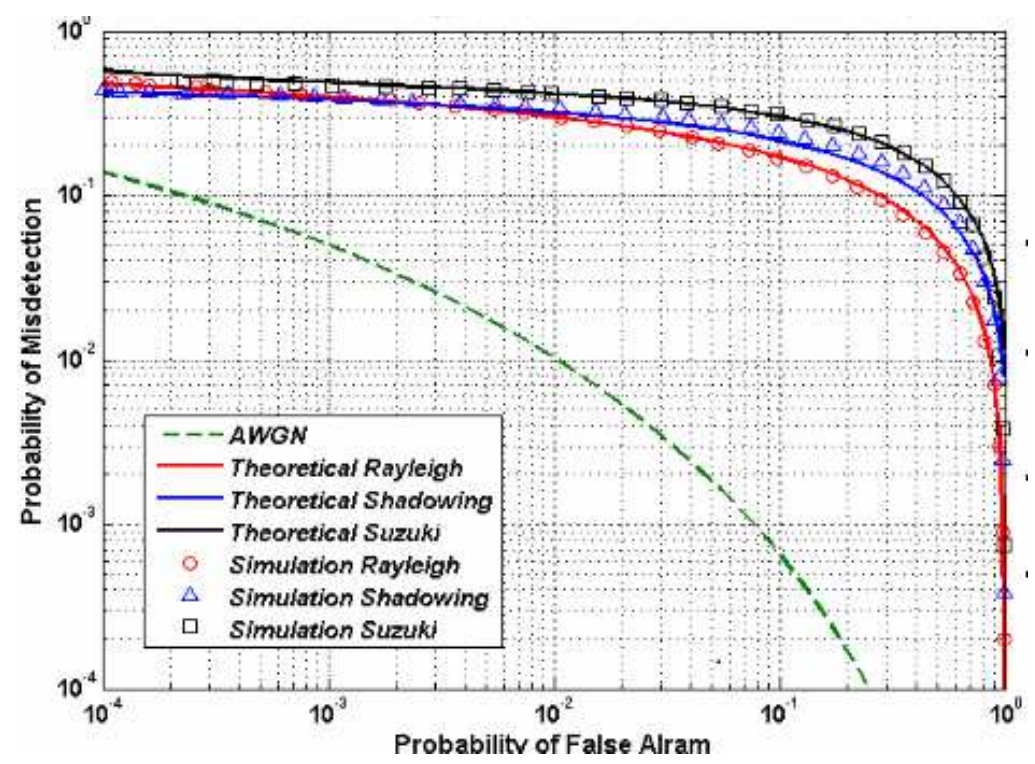

Fig. 4-1. Performance of Conventional Energy Detector under Various Channel $(\mathrm{SNR}=6 \mathrm{~dB}, \sigma=10 \mathrm{~dB})($ Kyperountas, . et all, 2007) 
Figure 4-1 shows the simulated and theoretical complementary ROC curves, for a conventional Energy Detector under the various fading environments with average $\mathrm{SNR}=6 \mathrm{~dB}$. As you can see that there is conventional severe performance degradation readily for energy detector.

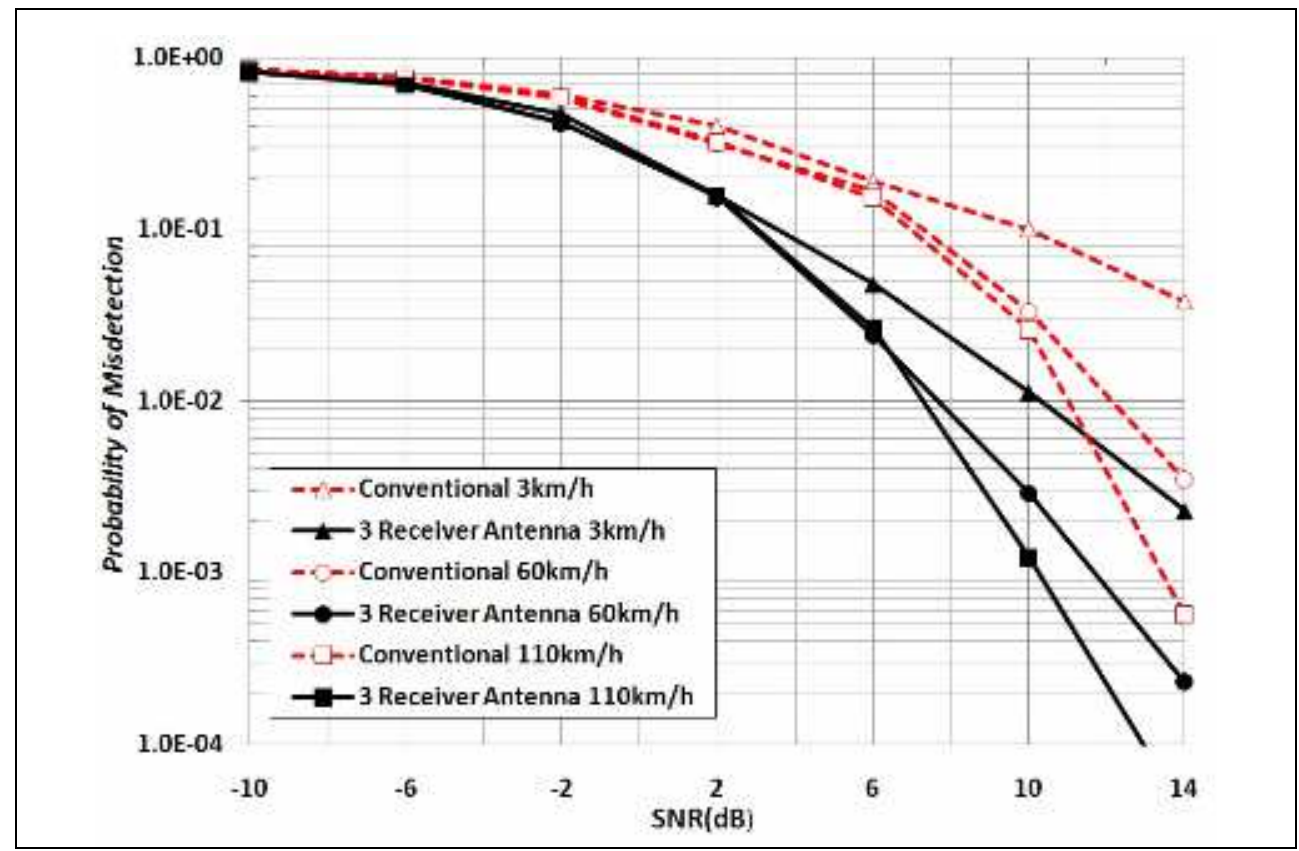

Fig. 4-2. Mobile Speed Effect for Proposed Method in terms of SNR vs. PMD

(Mobile Speed $=3,60,110 \mathrm{~km} / \mathrm{h}$ ) (Jong-Hwan Lee et al. 2008)

At three cases of mobile speed, the performance of the proposed spectrum sensing scheme is much better than conventional energy detector over the whole range of SNR values. Figure 4-2 shows that higher mobile speed may improve the sensing performance in range of high SNR. Because of the rapid channel variation, high mobile speed can overcome deep fading easily. When we require reliable spectrum sensing under the high mobile speed, the proposed scheme may be attractive method even though the complexity of multiple antennas is higher than other sensing methods.

In Figure 4-3 4-4, the impact of the sensing duration on the performance of the proposed and conventional energy detection schemes is investigated. Figure 4-3 shows the ROC curve (PD vs. PFA) for a mobile speed of $3 \mathrm{~km} / \mathrm{h}$, with the sensing duration as a parameter. As expected, as the sensing duration increases, the performances of both proposed and conventional energy detector are improved. However, similar performance is achieved for $6.6 \mathrm{~ms}$ and $9.9 \mathrm{~ms}$ sensing durations. As such, one can conclude that for sensing durations larger than $6.6 \mathrm{~ms}$ there is no substantial enhancement in the sensing performance. In addition, note that the performance of the proposed scheme with the sensing duration of 3.3 $\mathrm{ms}$ is similar to that of the conventional scheme for $6.6 \mathrm{~ms}$. This result shows that the use of multiple antennas is equivalent to an increase in the sensing duration with the conventional energy detection. 


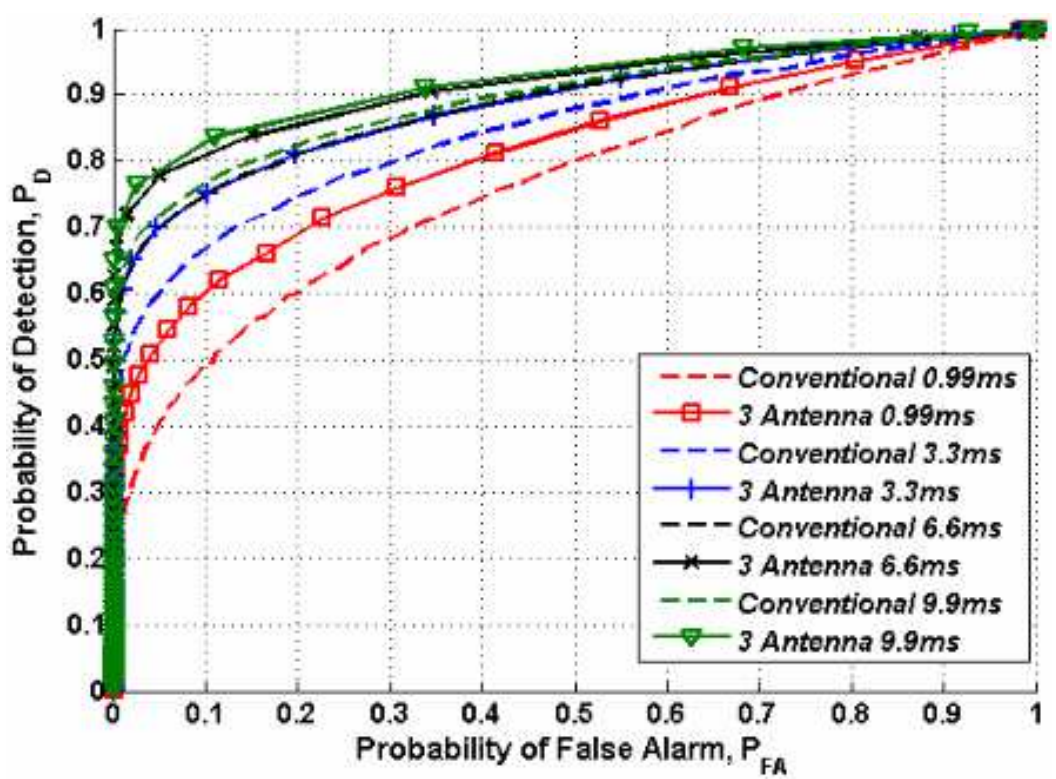

Fig. 4-3. ROC Curve of Proposed Method, for $3 \mathrm{~km} / \mathrm{h}$ mobile speed and with different sensing durations, PFA vs. PD (S.-H. Hwang et al., 2009)

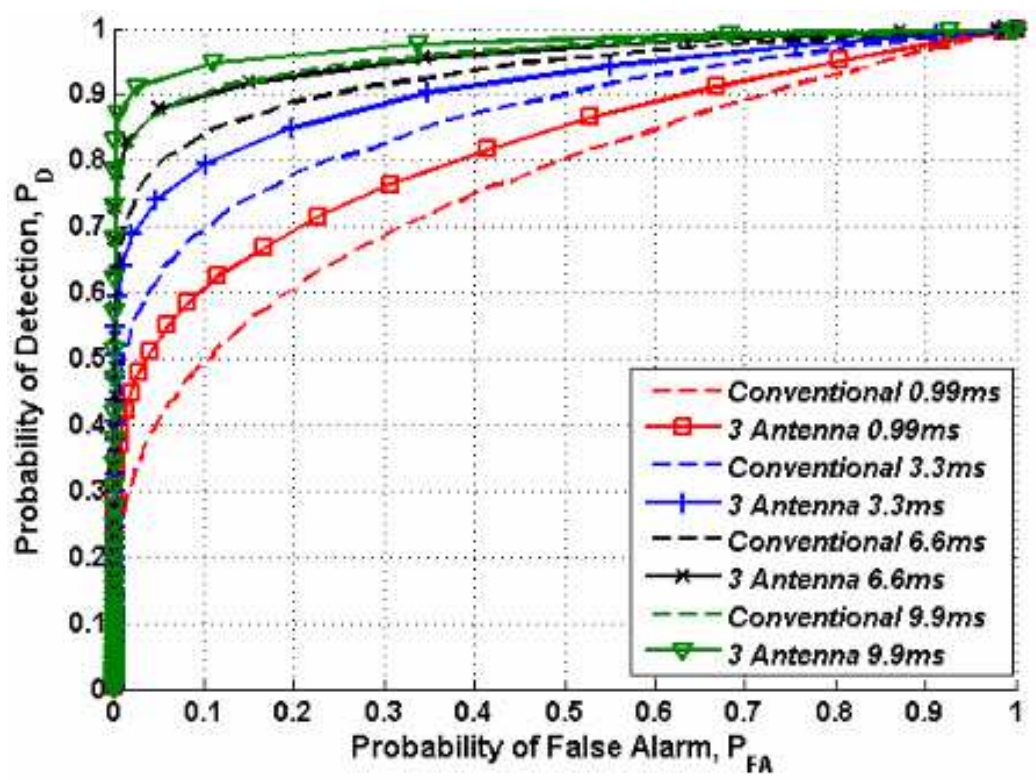

Fig. 4-4. ROC Curve of Proposed Method, for $110 \mathrm{~km} / \mathrm{h}$ mobile speed and with different sensing durations, $\mathrm{P}_{\mathrm{FA}}$ vs. $\mathrm{P}_{\mathrm{D}}$ (S.-H. Hwang et al., 2009) 
In Figure 4-4 results obtained for a mobile speed of $110 \mathrm{~km} / \mathrm{h}$ are provided, from which one can notice an improvement in performance when compared with Figure 4-3. When increasing the mobile speed, the Doppler spread increases and fast fading will be experienced. This translates into faster variations of the signal at the receive-side. The test statistic used with the energy detector is the received signal energy, which represents the area under the squared signal. For a given sensing duration, this can increase due to faster signal variations. That is, the signal energy can increase for fast fading. Note that the performance of the conventional scheme for the sensing duration of $6.6 \mathrm{~ms}$ is better than that of the proposed scheme for $3.3 \mathrm{~ms}$; this result indicates that the effect of the sensing duration is influenced by the mobile speed.

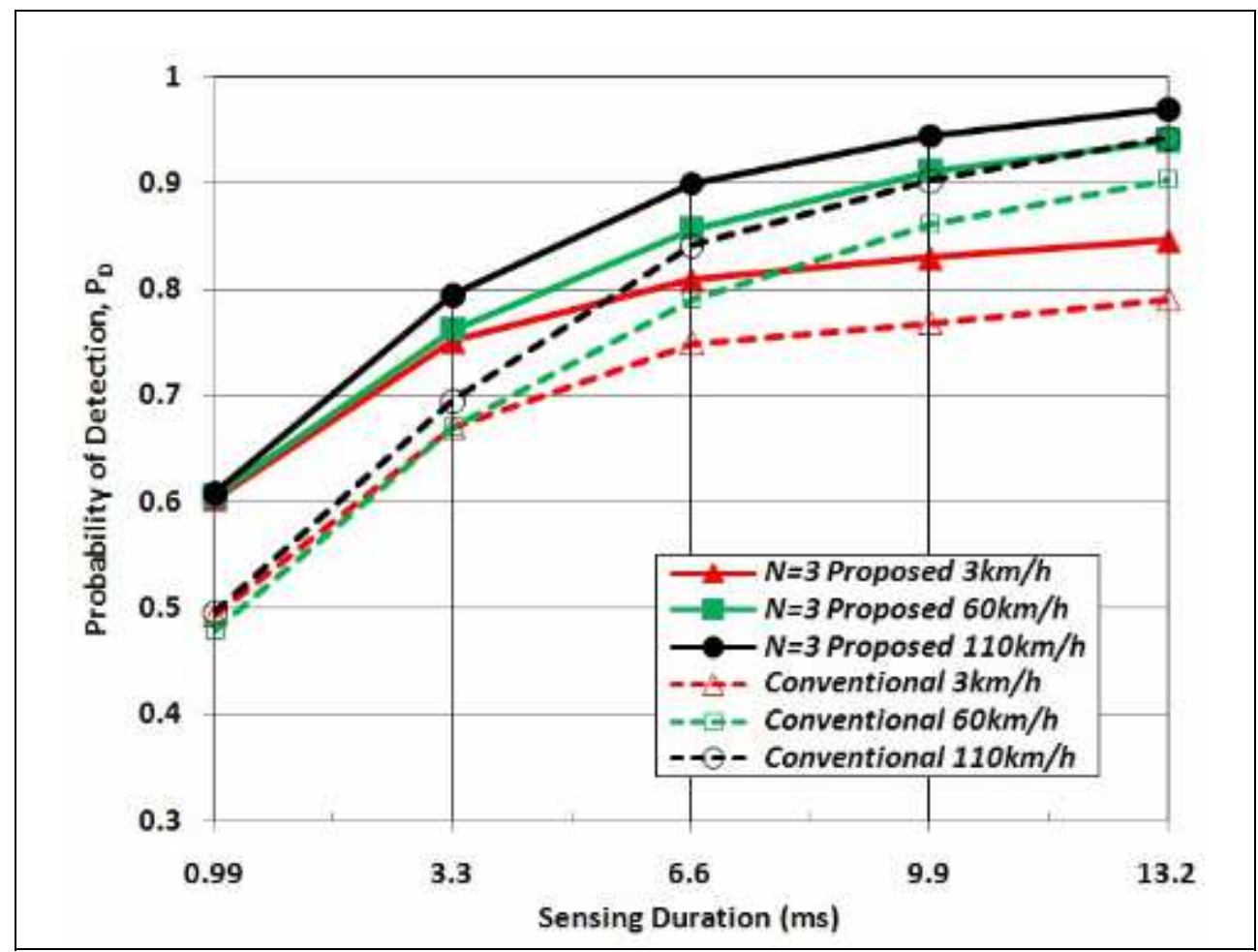

Fig. 4-5. Effect of Sensing Duration for Proposed Method at $P_{F A}=0.1$, Sensing Duration vs. $P_{D}$ (S.H.Hwang et al. 2009)

Figure 4-5 summarizes the performances in terms of the $P_{D}$ versus the sensing duration, for a $\mathrm{P}_{\mathrm{FA}}$ equal to 0.1. As the sensing duration increases, the performance is improved, regardless the mobile speed. An enhanced performance is attained for an increased speed of the mobile. A $P_{D}$ above 0.9 is obtained for a sensing duration exceeding $6.6 \mathrm{~ms}$ and a mobile speed of $110 \mathrm{~km} / \mathrm{h}$, and a sensing duration greater than $9.9 \mathrm{~ms}$ and $60 \mathrm{~km} / \mathrm{h}$ mobile speed. For a mobile speed of $3 \mathrm{~km} / \mathrm{h}$, the $P_{D}$ reaches around 0.85 even above $13.2 \mathrm{~ms}$ sensing duration. Note that to guarantee an acceptable sensing performance both $\mathrm{P}_{\mathrm{FA}}$ and $\mathrm{P}_{\mathrm{MD}}$ need to be less than 0.1 . 


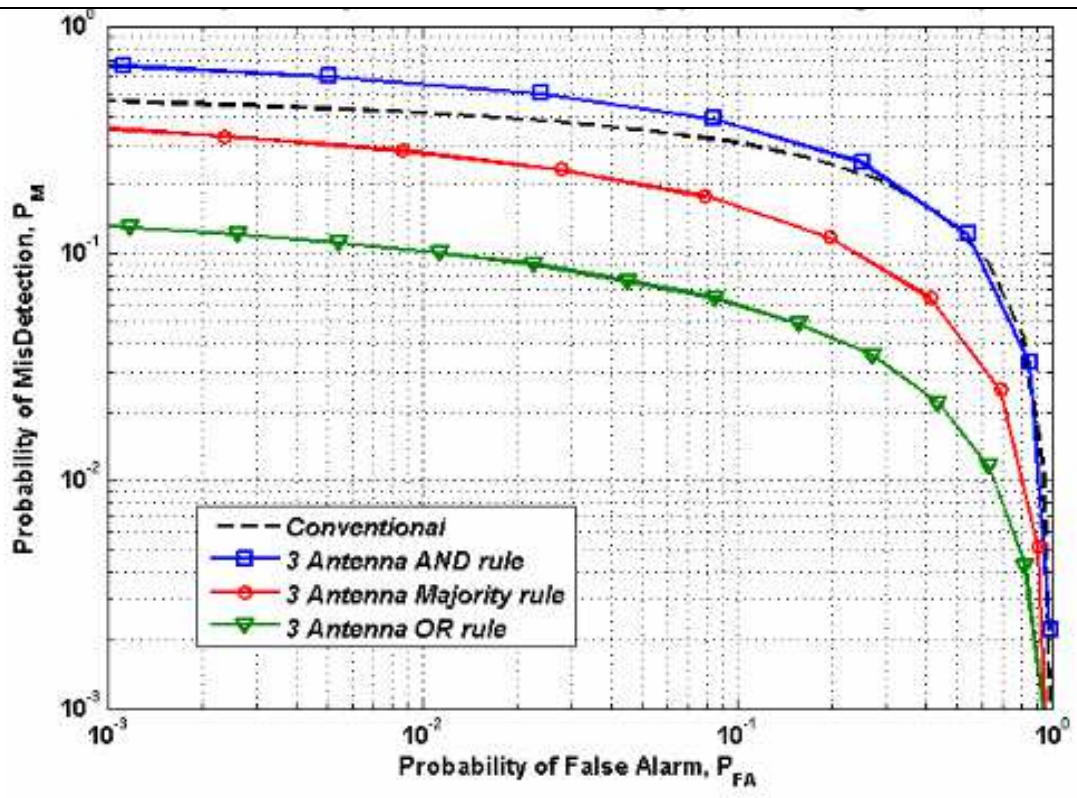

Fig. 4-6. Complementary ROC Curve of Proposed Sensing with Various Decision Rule $(\mathrm{N}=3$, Mobile Speed $=3 \mathrm{~km} / \mathrm{h}, \mathrm{SNR}=3 \mathrm{~dB})$, PFA vs. PM (S.-H. Hwang et al., 2009)

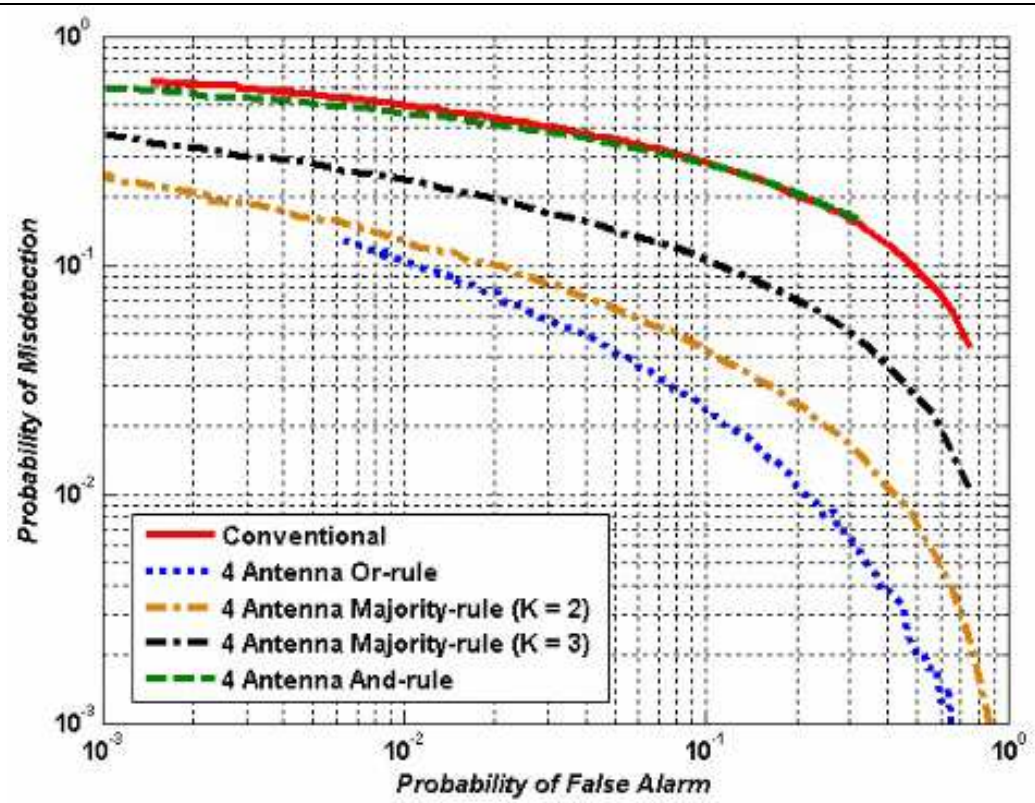

Fig. 4-7. Complementary ROC Curve of Proposed Sensing with Various Decision Rule ( $\mathrm{N}=4$, Mobile Speed $=3 \mathrm{~km} / \mathrm{h}, \mathrm{SNR}=3 \mathrm{~dB}), \mathrm{P}_{\mathrm{FA}}$ vs. $\mathrm{P}_{\mathrm{M}}$ 
Figure 4-6 shows only simulative results of three antennas aided energy detector under Suzuki fading channel in terms of Complementary ROC curve, other parameter same as before. The Figure 4-6 presents that the performance of the 'And-rule' is almost same as that of the conventional detector. 'Or-rule' shows the best performances.

Figure 4-7 shows the performance of proposed sensing with four antennas $(\mathrm{N}=4)$. When the number of antenna increases from two to four, the number of applicable criterions increases. For the case of four antennas, it is possible to employ two kinds of 'Majorityrules' where the reference values K can be two or three. The Figure shows that 'Orrule' -based sensing scheme can achieve the most reliable performance for four antennas as well. Therefore, we can see base on the previous results that 'Or-rule' is very effective to enhance the performance of the proposed scheme with multi-antennas (S.-H. Hwang et al., 2009).

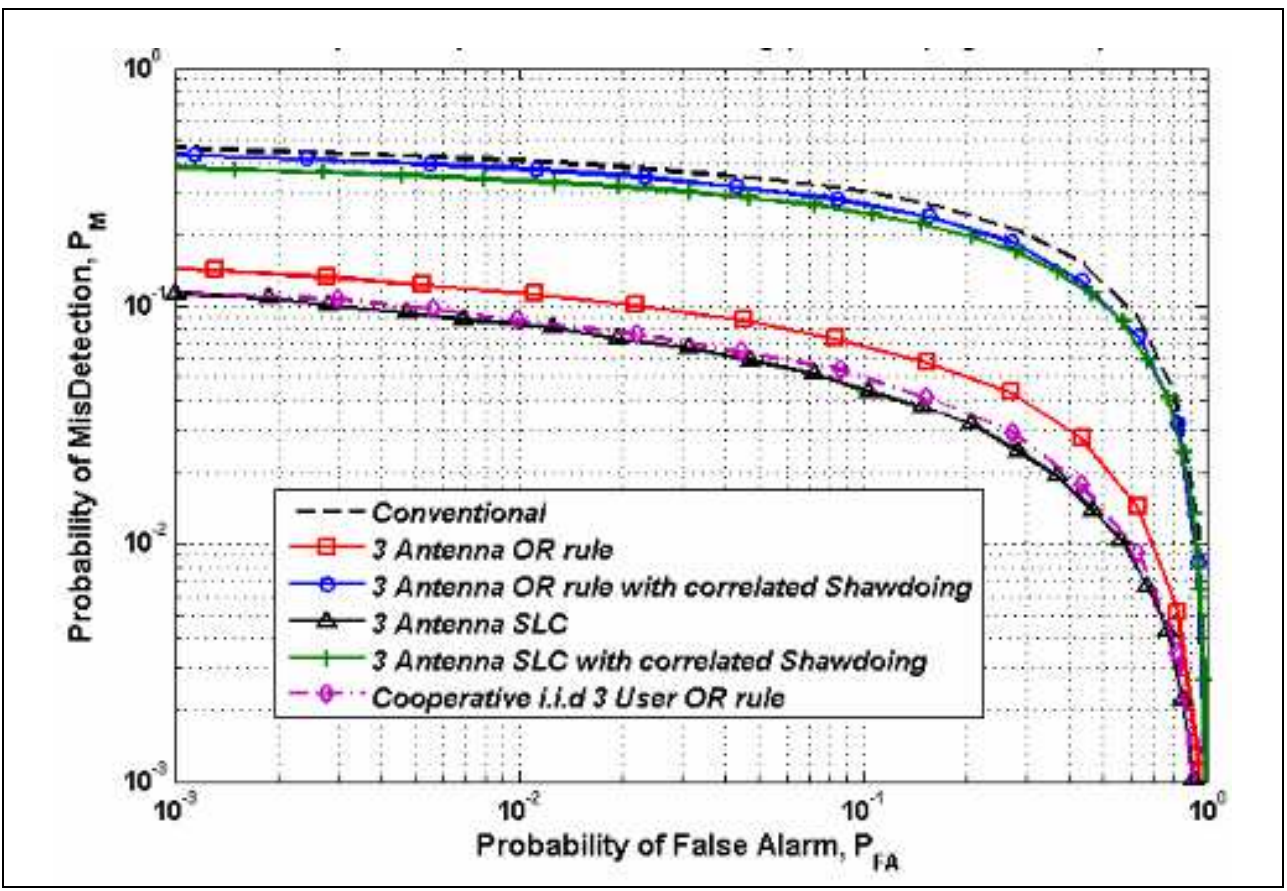

Fig. 4-8. Simulated complement ROC curve for 3 Antenna-aided Sensing under Suzuki channel with heavy correlated and un-correlated shadowing

$(\mathrm{SNR}=6 \mathrm{~dB}$, Mobile speed $=3 \mathrm{~km} / \mathrm{h}), \mathrm{P}_{\mathrm{FA}}$ vs. $\mathrm{P}_{\mathrm{M}}$

In the Figure 4-8 non-correlated case, performance of proposed scheme with OR fusion is worse $15 \%$ than that of square law combine (SLC). However, the performance degradation is less effective to proposed scheme than SLC scheme due to the correlation. Hence, we may say that proposed scheme is more robust to correlated shadowing effect. Other point of view, SLC gets an advantage for simplicity. Meanwhile proposed is more complex than SLC scheme, since multiple aided proposed scheme has energy detector devices as much as the number of antenna and also need 2 nd stage devices. 


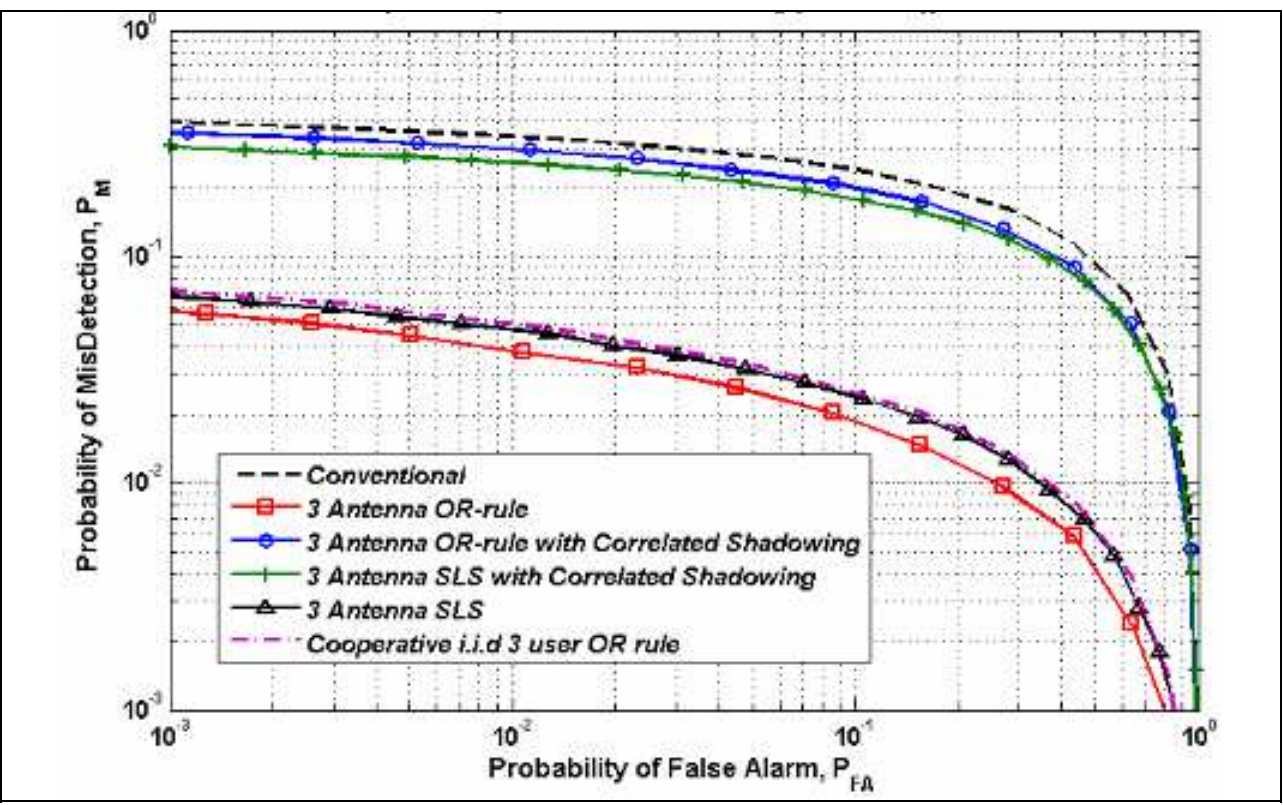

Fig. 4-9. Simulated Complement ROC curve for 3 Antenna-aided Sensing under Suzuki channel with Heavy Correlated and Uncorrelated Shadowing $(\mathrm{SNR}=6 \mathrm{~dB}$, Mobile speed $=110 \mathrm{~km} / \mathrm{h}), \mathrm{P}_{\mathrm{FA}}$ vs. $\mathrm{P}_{\mathrm{M}}$

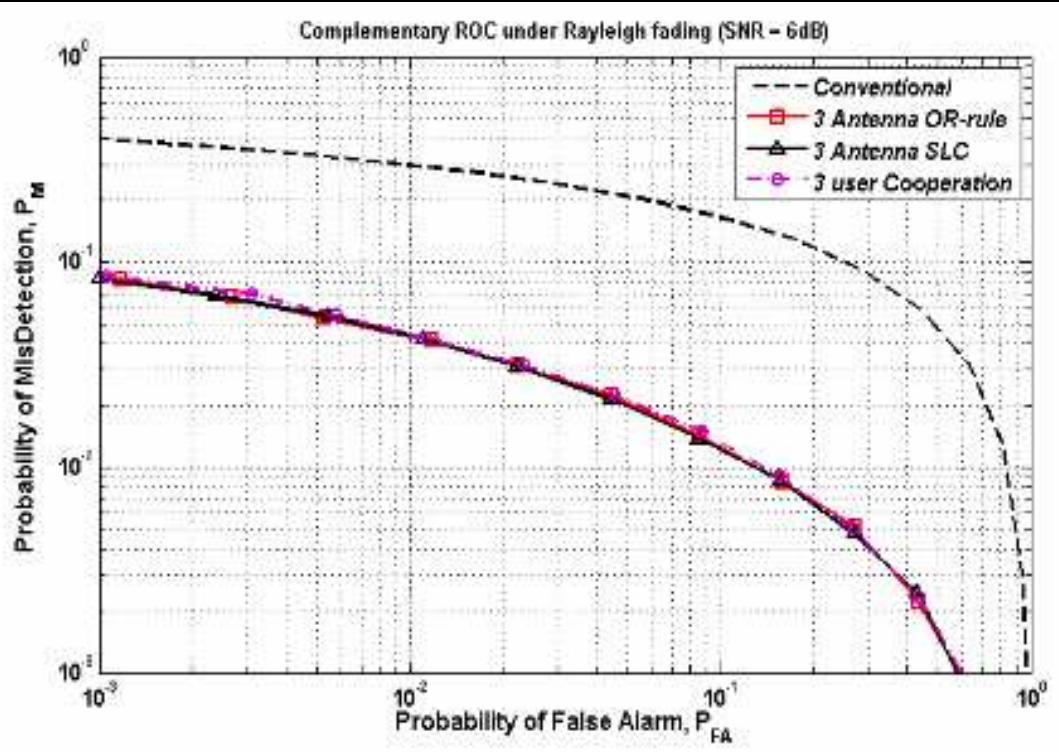

Fig. 4-10. Simulated Complement ROC curve for 3 Antenna-aided Sensing under Rayleigh Channel without Shawdoing Correlation $(S N R=6 \mathrm{~dB}$, Mobile speed $=110 \mathrm{~km} / \mathrm{h}), \mathrm{P}_{\mathrm{FA}}$ vs. $\mathrm{P}_{\mathrm{M}}$ 
In case of mobile speed up to $110 \mathrm{~km} / \mathrm{h}$ in Figure 4-9, proposed scheme with OR fusion can be achieved the highest performance of than that of other method non-correlated case. When we assume that there is only Rayleigh channel, the proposed scheme, SLC and cooperative sensing method have all same performance in the Figure 4-10.

\section{Conclusions and future work}

In the paper, we summarized the enabling spectrum sensing methods for cognitive radio. Among the other spectrum sensing method, we focus on the energy detector and derive detection probability under various channels such as AWGN, Rayleigh, Log-normal shadowing and Suzuki channel. We also explained the cooperative sensing concept and introduced novel spectrum sensing scheme which combines the energy detection with multiple receive antennas to improve the sensing reliability.

From the simulated results, our proposed scheme with Or-rule and soft receiver diversity such as SLC are both decreased probability of misdetection and false alarm and they are highly dependent on $\mathrm{c}$ and soed shadowing effect. However, the performance degradsoft rby the coand soft ris less effective to proposed scheme than SLC.le nsequently, we may say that proposed is moae robust to $c$ and soed shadowing effect. Now, we can conclude that performance of multiple aided energy detector spectrum sensing scheme can have advantages in some limioed case such as the hur pcoposed varisoft, low correlation.

The large operating bandwidths impose additional requirements on the radio frequencies (RF) components such as antennas and power amplifiers as well. According to resent study, the multiple receiver antenna scheme can have advantages for ultra-wideband spectrum sensing. Because it could manage more flexible wideband sensing. For the future research, we will continue to study spectral sensing method especially for the ultra-wideband frequency band using by multiple receiver antenna.

\section{Acknowledgement}

This research was supported by the International Research \& Development Program of the National Research Foundation of Korea (NRF) funded by the Ministry of Education, Science and Technology(MEST) of Korea(Grant number: F01-2009-000-10188-0)

\section{References}

A. Ghasemi and Elvino S. Sousa (2005) Collaborative spectrum sensing for opportunistic access in fading environments, in proc First IEEE International Symposium on DySPAN, pp.131-136.

A. H. Nuttall, (1975) Some integrals involving the QM function, in proc IEEE Transactions on Information Theory, vol. 21, no. 1, pp. 95 - 96.

A. Ghasemi and E. S. Sousa, (2007) Asymptotic performance of collaborative spectrum sensing under correlated log-normal shadowing, in proc IEEE Commun. Lett., vol. 11, no. 1, pp. $34-36$.

A. Sahai, N. Hoven, and R. Tandra (2004), Some fundamental limits on cognitive radio, in Proc. Allerton Conf. on Commun., Control, and Computing, Monticello, Illinois, Oct. 2004. 
Blostein, S.D.; Leib, H (2003). Multiple antenna systems: their role and impact in future wireless access, IEEE Communications Magazine, Volume 41, Issue 7,( July 2003.) pp. $94-101$

D. Cabric, S. Mishra, and R. Brodersen (2004), Implementation issues in spectrum sensing for cognitive radios, in Proc. Asilomar Conf. on Signals, Systems and Computers, vol. 1, Pacific Grove, California, USA, pp. 772 - 776, Nov. 2004.

D. Cabric, A. Tkachenko, and R. Brodersen (2006), Spectrum sensing measurements of pilot, energy, and collaborative detection, in Proc. IEEE Military Commun. Conf., Washington, D.C., USA, pp. 1 - 7, Oct. 2006.

Digham, F. F.; Alouini, M.-S.; Simon, M. K. (2007), On the Energy Detection of Unknown Signals Over Fading Channels, IEEE Transactions on Communications, Volume 55, Issue 1, (Jan. 2007)pp. 21-24

E. Visotsky, S. Kuffner, and R. Peterson (2005), On collaborative detection of TV transmissions in support of dynamic spectrum sharing in Proc. IEEE Int. Symposium on New Frontiers in Dynamic Spectrum Access Networks, Baltimore, Maryland, USA, pp. 338 - 345, Nov. 2005.

H. Urkowitz, (1967) Energy detection of unknown deterministic signals, in Proc. IEEE, vol. 55 , pp. $523-531$.

Ian F. Akyildiz, Won-Yeol Lee, Mehmet C. Vuran, Shantidev Mohanty, Next generation/dynamic spectrum access/cognitive radio wireless networks: A survey"

I. Mitola, J. and J. Maguire, G. Q., (1999) Cognitive radio: making software radios more personal, in proc IEEE Personal Commun Mag., vol. 6, no. 4, pp. 13 - 18.

J. G. Proakis(2001), Digital Communications, 4th ed. McGraw-Hill

J.H Baek, H.J Oh, J.H Lee, S.H Hwang (2008), Performance Improvements of Energy Detector for Spectrum Sensing in Cognitive Radio Environments: Verification using Multiple Antennas, Journal of IEEK (Apr. 2008), pp. 38-42,. .

Jong-Hwan Lee, Jun-Ho Baek, Seung-Hoon Hwang,. (2008) Collaborative Spectrum Sensing using Energy Detector in Multiple Antenna System, in proc ICACT 2008. 10th International Conference on Volume 1, pp. 427-430

Kyperountas, Spyros, Correal, Neiyer, Shi, Qicai, Ye, Zhuan (2007), Performance Analysis of Cooperative Spectrum Sensing in Suzuki Fading Channels, in Proc 2nd International Conference on CrownCom, pp. 428-434.

Mahapatra, R.; Krusheel, M. (2008), Cyclostationary detection for cognitive radio with multiple receivers, ISWCS '08. IEEE International Symposium, pp. 493 - 49.

M. Patzold, U. Killat, and F. Laue (1994), A deterministic model for a shadowed Rayleigh land mobile radio channel, in Proc. PIMRC '94, The Hague, Netherlands, pp. 12021210.

M. Patzold, Killat U., Laue F. (1996), A deterministic digital simulation model for Suzuki processes with application to a shadowed Rayleigh land mobile radio channel, in proc Vehicular Technology, IEEE Transactions on Volume 45, Issue 2, pp. 318-331.

M. Ghozzi, F. Marx, M. Dohler, and J. Palicot (2006), Cyclostationarity based test for detection of vacant frequency bands, in Proc. IEEE Crowncom,

O. A. Dobre, S. Rajan, and R. Inkol (2008), Exploitation of firstorder cyclostationarity for joint signal detection and classification in cognitive radio, in Proc. IEEE VTC Fall, pp. 1-5. 
P. K. Varshney (1997), Distributed detection and data fusion. NewYork: Springer-Verlag,

R. Tandra, A. Sahai (2005), Fundamental limits on detection in low SNR under noise uncertainty inProc. IEEE Int. Conf. Wireless Networks, Commun. and Mobile Computing, vol. 1, Maui, HI, pp. $464-469$

S.-H. Hwang, J.-H. Baek, O.A. Dobre (2009), Spectrum sensing using multiple antenna-aided energy detectors for cognitive radio, in Proc.IEEE CCECE, pp. 209-212.

T. S. Rappaport (2002), Wireless communications principles and practices, Prentice-Hall.

T. Weiss, J. Hillenbrand, A. Krohn, and F. Jondral(2003), Efficient signaling of spectral resources in spectrum pooling systems, in Proc. IEEE Symposium on Commun. and Veh. Tech nol., Eindhoven, Netherlands.

U. Gardner, WA, (1991) Exploitation of spectral redundancy in cyclostationary signals, in proc IEEE Signal Processing Mag., vol. 8, no. 2, pp. 14 - 36.

V. I. Kostylev (2002), Energy Detection of a Signal with Random Amplitude, in Proc. IEEE International Conference on Communication, vol. 3, pp. 1606 - 1610. 


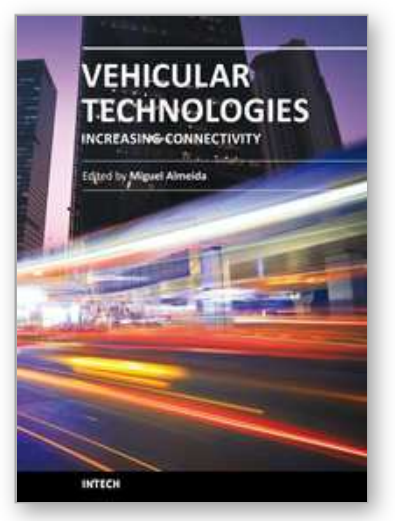

\author{
Vehicular Technologies: Increasing Connectivity \\ Edited by Dr Miguel Almeida
}

ISBN 978-953-307-223-4

Hard cover, 448 pages

Publisher InTech

Published online 11, April, 2011

Published in print edition April, 2011

This book provides an insight on both the challenges and the technological solutions of several approaches, which allow connecting vehicles between each other and with the network. It underlines the trends on networking capabilities and their issues, further focusing on the MAC and Physical layer challenges. Ranging from the advances on radio access technologies to intelligent mechanisms deployed to enhance cooperative communications, cognitive radio and multiple antenna systems have been given particular highlight.

\title{
How to reference
}

In order to correctly reference this scholarly work, feel free to copy and paste the following:

Seung-Hoon Hwang and Jun-Ho Baek (2011). Multiple Antenna-Aided Spectrum Sensing Using Energy Detectors for Cognitive Radio, Vehicular Technologies: Increasing Connectivity, Dr Miguel Almeida (Ed.), ISBN: 978-953-307-223-4, InTech, Available from: http://www.intechopen.com/books/vehicular-technologiesincreasing-connectivity/multiple-antenna-aided-spectrum-sensing-using-energy-detectors-for-cognitive-radio

\section{INTECH}

open science | open minds

\section{InTech Europe}

University Campus STeP Ri

Slavka Krautzeka 83/A

51000 Rijeka, Croatia

Phone: +385 (51) 770447

Fax: +385 (51) 686166

www.intechopen.com

\section{InTech China}

Unit 405, Office Block, Hotel Equatorial Shanghai

No.65, Yan An Road (West), Shanghai, 200040, China

中国上海市延安西路65号上海国际贵都大饭店办公楼 405 单元

Phone: +86-21-62489820

Fax: +86-21-62489821 
(C) 2011 The Author(s). Licensee IntechOpen. This chapter is distributed under the terms of the Creative Commons Attribution-NonCommercialShareAlike-3.0 License, which permits use, distribution and reproduction for non-commercial purposes, provided the original is properly cited and derivative works building on this content are distributed under the same license. 